\title{
Editorial
}

\section{The eradication of smallpox, a success story for modern medicine and public health: What lessons for the future?}

\author{
Eugenia Tognotti \\ History of Medicine and Human Sciences, Medical School, Department of Biomedical Sciences \\ University of Sassari, Viale San Pietro 07100 Sassari, Italy
}

J Infect Dev Ctries 2010; 4(5):264-266.

(Received and Accepted 15 May 2010)

Copyright $\odot 2010$ Tognotti et al. This is an open-access article distributed under the Creative Commons Attribution License, which permits unrestricted use, distribution, and reproduction in any medium, provided the original work is properly cited.

Thirty years ago, on 8 May 1980, the World Health Organization certified that smallpox had been eradicated globally $[1,12]$. For the first time in history, mankind had conquered a disease. It was certainly the greatest achievement of twentieth century medicine [2].

Smallpox, a devastating, highly contagious disease $[3,13]$, was caused by either of two virus variants named Variola major and Variola minor. Historical and epidemiological evidence suggests that South Asia was home to the more virulent strain of the disease, variola major, which sometimes mutated into the deadly haemorrhagic form of smallpox. Variola minor, also known as alastrim, was most common in Europe and North Africa, where mortality levels were lower. It killed up to half of those infected and seriously maimed survivors. Long-term side effects included the characteristic skin scars on the face, neck, and extremities, infertility in males and, occasionally, blindness due to corneal ulcerations (Figure 1) [3]. However, those who did survive enjoyed protective immunity from further infection.

Historically, smallpox was one of the most deadly diseases in the ancient world. The origin of smallpox is uncertain, but it is believed to have emerged in the human population around 10,000 BC, probably in India [1,4], likely crossing the species barrier by zoonotic spread. Natural mutations to the viral DNA, due to replication errors, caused Variola to change its molecular structure such that it could no longer sustain viability in any other animal host or environmental reservoir.

There have been numerous recorded epidemics throughout Europe, with high losses. Over time, the population gained increased immunity, and the
Figure 1. Characteristic skin scars on the face and neck.

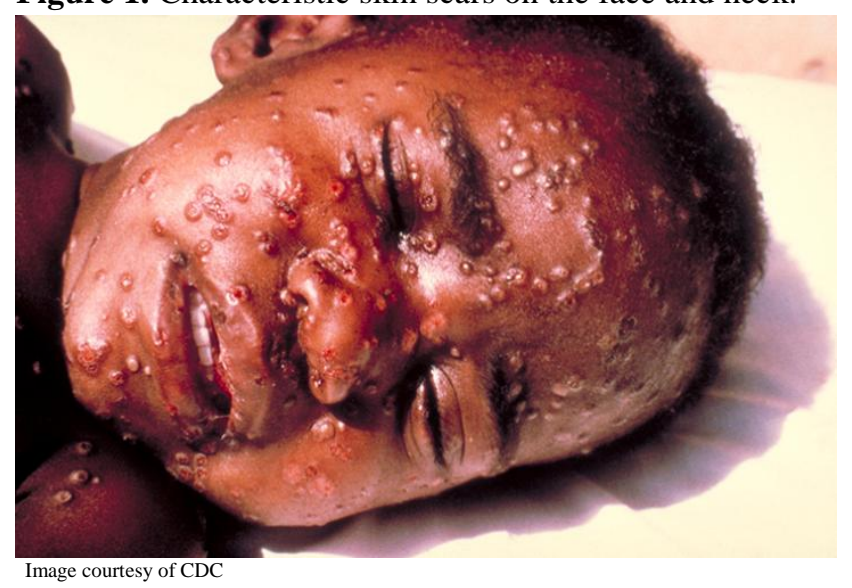

devastating impact of traditional infections decreased. On the contrary, the people of the New World had no history of prior exposure to the germ [5]. They had never experienced smallpox, measles or flu before their contact with Europeans. When the Spanish soldiers arrived in the 15th century, they introduced smallpox by contact with natives. A devastating epidemic broke out among the indigenous people, killing thousands of Native Americans.

In the era of global conquest which followed, European colonizers were aided by this powerful weapon: Eurasian germs became agents of conquest [6]. A 1713 smallpox epidemic in the Cape of Good Hope decimated the South African Khoi San people, rendering them incapable of resisting the process of colonization. European germs also wreaked annihilation on the aboriginal communities of Australia and New Zealand. In the seventeenth and eighteenth centuries, smallpox was a major endemic disease everywhere in the known world. 
Figure 2. Poster published by the World Health Organization at Geneva, Switzerland, after the declaration of the eradication of smallpox on Earth, May 8, 1980.

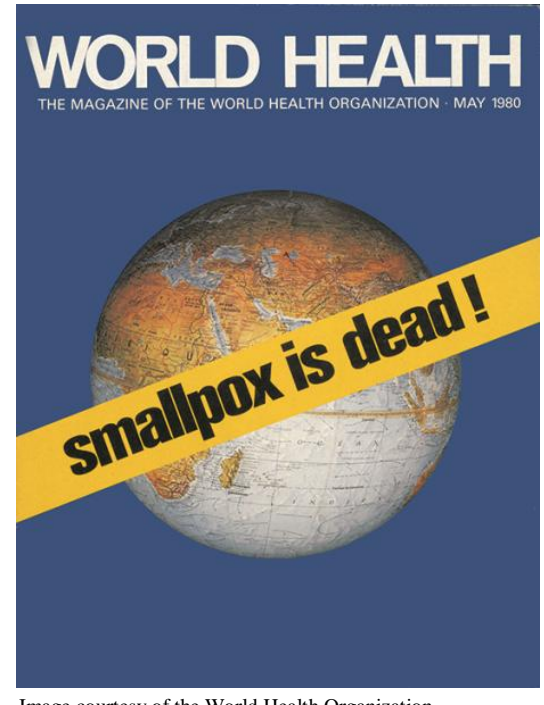

It was common knowledge that survivors of smallpox became immune to the disease. However, the most successful way of combating smallpox was with inoculation, which referred to the subcutaneous instillation of fresh matter taken from a ripe pustule of a person suffering from smallpox into non-immune individuals [7]. The practice of inoculation (or variolation) [ 8] was likely practiced in Africa, India, and China long before the 18th century, when it was introduced to Europe by an English aristocrat, Lady Mary Wortley Montague, wife of the British Ambassador to Turkey, at her return from Instanbul $[8,9]$. In the late 18th century an English doctor, Edward Jenner, conducted an experiment based on local lore. According to traditional knowledge, milkmaids who developed cowpox, a less serious disease, did not develop the deadly smallpox. Jenner therefore inserted into an incision on the arms of children pus extracted from a cowpox pustule from the hand of a milkmaid, and, after further successful tests, he proved conclusively that contracting cowpox provided immunity against smallpox without exposure to the disease itself [10]. It was the most important discovery ever made in medicine and the most life-saving health intervention for humankind [11]. Jenner called his idea "vaccination" from the word vaccinia, the latin translation of cowpox. In 1798 he published his findings: An Inquiry into the Causes and Effects of the Variolae vaccinae, $a$ Disease Known by the Name of Cow Pox. This work represented the first scientific attempt to control an infectious disease by the deliberate use of vaccination. The practice was initially regarded with suspicion in the medical community: inoculating a disease into a healthy body contradicted the principal purpose of medicine that -- since Hyppocrates -was to eliminate disease from the sick body.

Jenner envisioned the vaccine erasing smallpox from the earth rapidly, but it would take another 180 years. At the turn of the twentieth century, it was still a dangerous disease worldwide. In the 1950s a number of control measures were implemented, and smallpox was eradicated in many areas in Europe and North America, but in many developing countries the disease was endemic with catastrophic consequences. In 1959 the World Health Organization (WHO) launched an initiative to eradicate smallpox worldwide [12]. In that period the notion to conquer infectious diseases [13] dominated the international public health community. The World Health Organization had already adopted a global campaign to eradicate malaria with DDT, a pesticide first introduced after World II. It was believed that DDT was so powerful that it would help eliminate malaria forever. The quest to eliminate malaria anticipated the conquest of all contagious diseases thanks to penicillin and modern antibiotics [14]. In 1967, prominent epidemiologist at Johns Hopkins and advisor to the WHO, Aidan Cockburn, noted that "eradication", the new concept in public health, had advanced in the past two decades, and had replaced "control" as an "objective" [15]. According to Cockburn, eradication was "entirely practical" for all communicable diseases. So, he argued, "it seems reasonable to anticipate that within some measurable time, such as 100 years, all the major infections will have disappeared" [15]. In this triumphant scientific climate, in 1967, a global campaign began under the guardianship of the WHO, based on the involvement of a range of international and national aid donors, in a great variety of geographical, political, social, economic and cultural contexts [16]. The campaign to eradicate smallpox adopted a strategy of containment and surveillance [17]. The eradication teams actively tracked the disease, moving with a "recognition card" showing a baby affected by smallpox, to show people what the illness looked like. The fact that humans are the only reservoir for smallpox infection, and that carriers did not exist, played a significant role in the eradication. Finally, WHO announced in 1980 that smallpox had become the first disease ever to be eradicated by intentional human action (Figure 2) [13]. 
Historical analysis of all phases of the global eradication of smallpox is significant from an academic viewpoint, but also from the side of international public health [18].

There are ethical aspects [1] and lessons [18] to be learned by the success of the eradication of small pox and, in parallel, by the failure of the WHO global malaria eradication program that ended in 1972 $[19,20,21]$ :

- Recognition that public health policy cannot be imposed solely from above

- The crucial role of surveillance for smallpox cases in the strategy of the campaign

- The encouragement of research initiatives at every level

- The central importance of community participation, the mobilising of local administration, as well as the political and civilian support for public health programmes that need large-scale immunisation and isolation

- The significance of adapting public health activity and strategies of communication to innumerable local cultural customs, behaviours and concerns

These lessons remain valid today in the initiatives for guinea-worm eradication and poliomyelitis eradication in the Americas and western Asia. The upcoming international symposium, "Smallpox Eradication after 30 years: Lessons and Legacies", hosted by the Oswaldo Cruz Foundation, Rio de Janeiro, (24-27 August 2010, Brazil ) will be an important occasion to recognize these lessons and their implications for contemporary disease control programmes worldwide.

\section{References}

1. Koplow DA (2003) Smallpox: the Fight to Eradicate a Global Scourge University of California Press, Berkeley, CA, $274 \mathrm{p}$.

2. Behbehani AM (1983) The smallpox story: life and death of an old disease. Microbiol Rev 47: 455-509.

3. Jezek Z, Hardjotanojo W, Rangaraj AG (1981) Facial scarring after varicella. A comparison with variola major and variola minor. Am J Epidemiol 114: 798-803.

4. Hopkins DR (2002) The Greatest Killer: Smallpox in history. University of Chicago Press, $400 \mathrm{p}$.

5. Li Y, Carroll DS, Gardner SN, Walsh MC, Vitalis EA, Damon IK (2007) On the origin of smallpox: correlating variola phylogenics with historical smallpox records. Proc Natl Acad Sci USA 104: 15787-92.
6. Fenn EA (2000) Biological Warfare in Eighteenth-Century North America: Beyond Jeffery Amherst. The Journal of American History 4: 1552-1580.

7. Gross CP, Sepkowitz KA (1998) The myth of the medical breakthrough: smallpox, vaccination, and Jenner reconsidered. Int J Infect Dis. 3: 54-60.

8. Stearns RP (1950) Remarks upon the introduction of inoculation for smallpox in England. Bull Hist Med 24: 103-122.

9. Halsband, R (1956) The Life of Lady Mary Wortley Montagu (Illustrated ed.) Oxford: Clarendon Press.

10. Willis NJ (1997) Edward Jenner and the eradication of smallpox. Scott Med J 42: 118-121.

11. Atkinson W, Hamborsky J, McIntyre L, Wolfe S (eds.) (2005) Smallpox Epidemiology and Prevention of VaccinePreventable Diseases. The Pink Book. (9th ed.) Washington DC: Public Health Foundation. pp. 281-306.

12. World Health Organization (1980) The Global Eradication of Smallpox: Final Report of the Global Commission for the Certification of Smallpox Eradication. Geneva: World Health Organization; Global Commission for Certification of Smallpox Eradication., p.11.

13. Burnet F and White DO (1972) Natural History of Infectious Disease (4th ed.) Cambridge: Cambridge University Press. pp. 1-21.

14. Hinman EH (1966) World Eradication of Infectious Diseases. Springfield, IL: CC Thomas, 223 p.

15. Cockburn A (1963) The Evolution and Eradication of Infectious Diseases. Baltimore: Johns Hopkins University Press, $255 \mathrm{p}$.

16. Fenner F., Henderson D.A., Arita I., Jezek Z. and Ladnyi D. (1988) Smallpox and its eradication. Geneva, World Health Organization, 1988.

17. Henderson DA (1982) A successful eradication campaign: discussion. Reviews of infectious diseases 4: 923-924.

18. Hinman AR and Hopkins DR (1988) Lessons from previous eradication programs. In: Dowdle WR, Hopkins DR. eds. The eradication of infectious diseases: report of the Dahlen Workshop on the Eradication of Infectious Diseases. Clichester: John Wiley \& Sons, pp. 19-32.

19. Henderson DA (1988) Eradication: lessons from the past. Bull World Health Organ. 76 (Suppl 2): 17-21.

20. Farid MA (1980 The malaria program - from euphoria to anarchy. World Health Forum 1: 8-22.

21. Yekutiel P (1981) Lessons from the big eradication campaigns. World health forum 2: 465-490.

\section{Corresponding Author}

Prof. Eugenia Tognotti

History of Medicine and Human Sciences

Medical School Department of Biomedical Sciences

University of Sassari Viale San Pietro

07100 Sassari, Italy

$++39079228210$

++079237866

tognotti@uniss.it

tognotti@tiscali.it

Conflict of interests: No conflict of interests is declared. 